\title{
ERRATUM
}

\section{Steinernema jeffreyense n. sp. (Rhabditida: Steinernematidae), a new entomopathogenic nematode from South Africa - ERRATUM}

\author{
A.P. Malan, R. Knoetze and L.R. Tiedt
}

doi:10.1017/S0022149X15000097, published by Cambridge University Press, 11 March 2015.

First Published Online 10 June 2015

The first author's name was misspelt in the running header of the above mentioned article. The error has been rectified in the online PDF and HTML copies of this article.

\section{Reference}

Malan, A.P., Knoetze, R., Tiedt, L.R. Steinernema jeffreyense n. sp. (Rhabditida: Steinernematidae), a new entomopathogenic nematode from South Africa. Journal of Helminthology. Published online by Cambridge University Press 11 March 2015 , doi:10.1017/S0022149X15000097. 